\title{
Relationship Research between Subjective Well-being and Unsafe Behavior of Coal Miners
}

\author{
Ji-Zu Li ${ }^{1}$, Ya-Ping Zhang ${ }^{1 *}$, Xiao-Jia Wang ${ }^{1}$, Guo-Rui Feng ${ }^{1}$, Bai-Sheng Zhang ${ }^{1}$, Tian-Ri Wang ${ }^{1}$, \\ Xiao-Guang Liu ${ }^{1}$, Jiao-Jiao Qu ${ }^{1}$ \\ ${ }^{1}$ Taiyuan University of Technology, PR CHINA
}

Received 1 June 2017 • Revised 9 September 2017 • Accepted 18 September 2017

\begin{abstract}
In recent years, China's coal mine safety accidents are frequently. Human factors are the main cause of coal mine safety accidents, and miners' unsafe behavior is one of the main forms of human factors. It is necessary to conduct in-depth study on the unsafe behavior of miners to ensure the safety of coal mine. In this study, the relationship between coal miners' subjective well-being and unsafe behavior was examined from the perspective of ordinary miners' well-being. And then the influencing factors of miners' unsafe behavior were analyzed. Two hundred miners were selected randomly for this study in Datong Coal Mine Group of Shanxi Province. Then, a questionnaire was completed by the 200 miners respectively, and a valid sample of 184 responses was collected. SPSS23.0 software was used to organize and analyze these data. The conclusions show that the hypotheses were all confirmed, and subjective well-being has a significant impact on miners' unsafe behavior, positive emotion has a negative influence on miners' unsafe behavior, negative emotion has a significant positive impact on miners' unsafe behavior, and life satisfaction has a significant negative relationship with miners' unsafe behavior. Thus, some countermeasures were put forward for coal mine managers to enhance miners' subjective well-being and reduce their unsafe behaviors.
\end{abstract}

Keywords: subjective well-being, unsafe behavior, relationship research, questionnaire survey, safety education and training

\section{INTRODUCTION}

In recent years, coal mining enterprises in China have encountered many difficulties in the process of development. And safe production becomes a thorny problem. According to the statistics of State Administration of Coal Mine Safety, from January 2015 to July 2017, the number of China's overall Major Coal Mine Accident was 57, killed 416 people. Many factors affect the safety of coal mine production. And miners' unsafe behavior was proven to be an important cause of coal mine accidents, based on 71 Major Coal Mine Accidents, from 2005 to 2010 (Li, N. W., \& Ji, D. J., 2011). In the research of gas outburst accidents, gas explosion accidents and mine water accidents, Chen, Qi, Long, and Zhang (2012) found that human factors accounted for $94.09 \%$ among the causes of these accidents. Due to the harsh environmental conditions of coal mine, miners' mental stress is far more than ordinary people, and their spiritual needs are relatively high. If these spiritual needs are not being met, miners' subjective happiness will continually decline, which will lead miners to a lot of unsafe behaviors in the work. Therefore, there is some correlation between miners' subjective well-being and their unsafe behavior. If the mechanism between miners' subjective well-being and unsafe behavior can be identified, the effective targeted measures to improve miners' safe behavior level can be proposed, and the safe production of coal mines can be guaranteed.

Across a sample of 123 countries, Tay and Diener (2011) found that need fulfillment was consistently associated with subjective well-being. Chen, Van Assche, Vansteenkiste, Soenens, and Beyers (2015) investigated two samples

\footnotetext{
(C) Authors. Terms and conditions of Creative Commons Attribution 4.0 International (CC BY 4.0) apply.

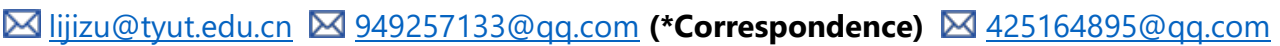




\section{Contribution of this paper to the literature}

- The significance of the present study lies in its contributions to the psychological safety management measures and safety education and training strategies for coal mine management personnel to control miners' unsafe behavior.

- The mechanism of different dimension of subjective well-being on miners' unsafe behavior is clarified.

- The hypotheses are all supported, and coal mine managers should pay more attention to miners' psychological health.

respectively in South Africa and China, and then showed that satisfaction of the psychological needs contributed to well-being above and beyond safety satisfaction. Various studies have established the relationship between job satisfaction and organizational citizenship behavior, and further findings showed that job satisfaction mediated the relationship between positive emotions and organizational citizenship behavior (Ziegler, R., Schlett, C., Casel, K., \& Diehl, M., 2012).

Through many previous studies, it can be known that satisfaction of the psychological needs was closely related to subjective well-being, and job satisfaction had a significant impact on the behavior of employee. However, these researches did not explicitly point out the relationship between subjective well-being and unsafe behavior. Thus, this paper aims to explore the mechanism of subjective well-being impact on miners' unsafe behaviors, and then put forward some suggestions to coal enterprise managers to improve the level of coal mine safety management.

\section{THEORIES AND HYPOTHESES}

Coal mine accidents were often caused by human factors, such as miners' unsafe behavior and unsafe psychology. Psychological safety education could ensure miners' safe behavior and then reduce coal mine accidents (Liu, G. Y., \& Luo, C. L., 2012). Li, Jiang, Yao, and Li (2013) pointed out that emotional exhaustion mediated the relationship between psychological demands and safety outcomes. Subjective well-being is one of the psychological demands. Tay and Diener (2011) divided subjective well-being into three dimensions, including life evaluation, positive feelings, and negative feelings. Based on all above the theoretical basis and empirical evidences, this study selected positive emotion, negative emotion, and life satisfaction to measure subjective well-being. And the following hypotheses can be asserted.

H1. Miners' subjective well-being is related to their unsafe behavior.

H2. Miners' positive emotion has negative impact on unsafe behavior.

H3. Miners' negative emotion has positive impact on unsafe behavior.

H4. Miners' life satisfaction has negative effect on unsafe behavior.

Theoretical model is shown in Figure 1.

\section{QUESTIONNAIRE DESIGN AND DISTRIBUTION}

In order to measure the relationship between subjective well-being and unsafe behavior of coal miners, this study selected 200 miners of Datong coal mine in Shanxi Province as the research object, including coal diggers, tunneling workers, transportation workers, ventilation workers, electromechanical workers, belt driver, and et al. And a questionnaire was designed to collect research data, based on the actual working environment of coal mine and previous research achievements of other scholars.

The whole questionnaire was divided into three parts. The first part was personal information scale, including miners' age, length of service, education level and marital status. The second part of the questionnaire was coal miners' subjective well-being scale, which contained three dimensions, namely positive emotion, negative emotion and life satisfaction. The emotion dimensions were measured through 20 questions based on the emotion scale

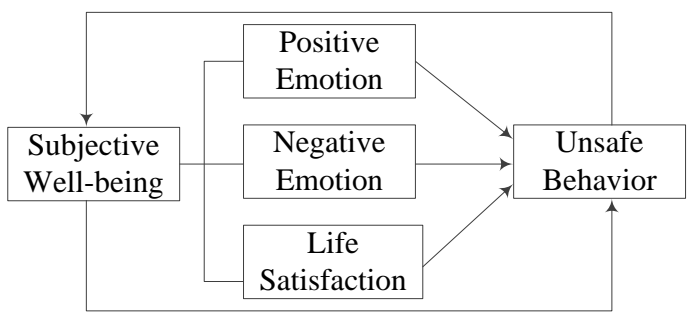

Figure 1. Theoretical model 
Table 1. Miners' subjective well-being scale

\begin{tabular}{|c|c|c|}
\hline Scale name & Dimensions & Questions \\
\hline \multirow{25}{*}{$\begin{array}{l}\text { Subjective well- } \\
\text { being }\end{array}$} & \multirow{10}{*}{ Positive emotion } & My life is moving in the direction I expected now. \\
\hline & & My future is beautiful. \\
\hline & & I like myself. \\
\hline & & I can cope with anything that happens. \\
\hline & & I feel that people love me and trust me. \\
\hline & & I feel close to the people around me. \\
\hline & & I feel I can do whatever I want to do. \\
\hline & & I have a lot of energy. \\
\hline & & I always smile and laugh. \\
\hline & & I have a clear and a creative mind. \\
\hline & \multirow{10}{*}{ Negative emotion } & I want to change some parts of my life. \\
\hline & & I feel the best days of my life have passed. \\
\hline & & I feel like something is wrong with me. \\
\hline & & I feel like a loser. \\
\hline & & When I'm alone, no one is with me. \\
\hline & & I have lost interest in other people, and don't care about them. \\
\hline & & My life is like a cookie cutter. \\
\hline & & I don't want to do anything at all. \\
\hline & & As if you can't find anything interesting to do. \\
\hline & & My train of thought is always in a circle. \\
\hline & \multirow{5}{*}{ Life satisfaction } & Most of my life now is close to my ideal state. \\
\hline & & My life condition is very good. \\
\hline & & I am satisfied with my life. \\
\hline & & So far, I've got a lot of what I want. \\
\hline & & If I could live a second time, I would not make any change. \\
\hline
\end{tabular}

Table 2. Miners' unsafe behavior scale

\begin{tabular}{|c|c|}
\hline Scale name & Questions \\
\hline \multirow{10}{*}{$\begin{array}{l}\text { Unsafe } \\
\text { behavior }\end{array}$} & I sometimes split the mechanical devices and other security configurations. \\
\hline & I sometimes ignore the security warning flag for the wrong operation. \\
\hline & I sometimes fail to preserve the safety protection device. \\
\hline & In the absence of human supervision, I sometimes use no security facilities, equipment or tools. \\
\hline & In order to facilitate the convenience, I sometimes use the hand instead of tools to operate. \\
\hline & I sometimes climb and sit in an unsafe position. \\
\hline & I sometimes wear the wrong protective equipment that does not meet requirements. \\
\hline & In order to complete the work more easily, I sometimes violate the rules and regulations. \\
\hline & I sometimes pretend to understand, and make wrong operation. \\
\hline & I occasionally foolhardy adventure in working. \\
\hline
\end{tabular}

proposed by Chu and Murrmann (2006). The life satisfaction dimension was measured through 5 questions based on the life satisfaction scale made by Kushlev and et al (Kushlev, K., Heintzelman, S. J., Lutes, L. D., Wirtz, D., Oishi, S., \& Diener, E., 2017). Miners' subjective well-being scale is shown in Table 1. The third part was miners' unsafe behavior scale, which was made up of 10 questions based on the achievements of miners' unsafe behaviors (Zhang, Y. T., Wei, X. X., \& Li, J. Z., 2015; Li, J. Z., Zhang, Y. P., Liu, X. G., Liu, Y. L., \& Wang, T. R., 2017). Unsafe behavior scale is shown in Table 2.

Miners' subjective well-being scale adopted Likert 5-point scoring method. The answer to each question was divided into five levels, including absolutely disagree, disagree, uncertain, agree, totally agree, and scored from 1 to 5 points respectively. Unsafe behavior scale adopted Likert 5-point scoring method scoring the way back. The higher the score, the better safe behavior level of miners.

Questionnaires were randomly distributed in the fixed-point, and the research objects were from the departments that unsafe behaviors frequently occurred. These objects were unified and surveyed in the weekly safety inspection meeting. Anonymous model was used by miners to complete the questionnaire survey, thus their psychological pressure could be eliminated and the quality of the questionnaire could be improved. The format and requirements of the questionnaire were detailed before the survey, and the results were taken back on the spot. A total of 200 questionnaires were distributed and 184 valid results were recovered. The effective response rate was $92 \%$. 
Table 3. Statistical analysis results of miners' personal information

\begin{tabular}{|c|c|c|c|c|}
\hline & Feature classification & Number & Percentage & Cumulative percentage \\
\hline \multirow{4}{*}{ Age } & 25 years old and below & 19 & $10.3 \%$ & $10.3 \%$ \\
\hline & $26-35$ years old & 114 & $62 \%$ & $72.3 \%$ \\
\hline & 36-45years old & 43 & $23.4 \%$ & $95.7 \%$ \\
\hline & 46 years old and above & 8 & $4.3 \%$ & $100 \%$ \\
\hline \multirow{4}{*}{$\begin{array}{l}\text { Length of } \\
\text { service }\end{array}$} & Below 5 years & 80 & $43.5 \%$ & $43.5 \%$ \\
\hline & $6-10$ years & 83 & $45.1 \%$ & $88.6 \%$ \\
\hline & $11-20$ years & 12 & $6.5 \%$ & $95.1 \%$ \\
\hline & 21 years and above & 9 & $4.9 \%$ & $100 \%$ \\
\hline \multirow{4}{*}{$\begin{array}{l}\text { Education } \\
\text { level }\end{array}$} & Junior high school & 14 & $7.6 \%$ & $7.6 \%$ \\
\hline & High school and technical secondary school & 118 & $64.1 \%$ & $71.7 \%$ \\
\hline & Junior College & 48 & $26.1 \%$ & $97.8 \%$ \\
\hline & Undergraduate & 4 & $2.2 \%$ & $100 \%$ \\
\hline \multirow{2}{*}{$\begin{array}{l}\text { Marital } \\
\text { status }\end{array}$} & Married & 155 & $84.2 \%$ & $84.2 \%$ \\
\hline & Unmarried & 29 & $15.8 \%$ & $100 \%$ \\
\hline
\end{tabular}

\section{QUESTIONNAIRE ANALYSIS}

The objects of this survey were all male. Thus, miner's gender was not a research element of this study and did not appear in the personal information scale. The results of miners' personal information of the survey are shown in Table 3.

It can be seen from the statistical results in Table 3 that the proportion of ages below 35 years old up to $72.3 \%$, the proportion of length of service above 6 years is $56.5 \%$, and the proportion of education level below Junior College is $71.7 \%$, which means that most miners have lower education level, better physical fitness and more working skills. Married miners account for $84.2 \%$ of the total number of the survey objects. All above the results are in line with the general characteristics of coal miners, and the objects of this study have a certain representation.

Then, SPSS23.0 software was used to measure the reliability and validity of the questionnaire. After analysis, the Coefficient of Cronbach's a of subjective well-being scale is 0.883 , and the positive emotion scale is 0.729 , the negative emotion scale is 0.792 , and the life satisfaction scale is 0.818 . The Coefficient of Cronbach's a of unsafe behavior scale is 0.793 . All the Coefficients of Cronbach's a are above 0.7 , indicating that the questionnaire has good reliability.

Kaiser-Meyer-Olkin (KMO) method and Bartlett Sphericity test were used to examine the validity of the questionnaire. The KMO value of subjective well-being scale is 0.778 , and the Bartlett Sphericity test value is 0.000 ( $<0.005)$. The KMO values of the three dimensions of the subjective well-being scale are $0.752,0.797$ and 0.737 respectively. And the KMO value of unsafe behavior scale is 0.768 . All the KMO values of the scales are above 0.7 , which means that the survey data are strongly correlated and the questionnaire has good validity.

And then, descriptive statistical analysis was carried out to investigate the basic situation of the objects. Statistical results indicate that the average score of miners' subjective well-being is 2.8 , the three dimensions of the subjective well-being scale are 3, 2.5 and 3 respectively, and miners' unsafe behavior is 3.5, which means that miners' subjective well-being is at a moderate level and miners' safety standards are better. It can be seen that the sample of this study is substantially obeying the normal distribution.

\section{DATA INSPECTION AND ANALYSIS}

Correlation test was used to inspect the relationship between the three dimensions of subjective well-being and unsafe behavior. And the correlation coefficients are shown in Table 4. The calculation results show that positive emotion is significantly negative correlated with unsafe behavior $(\mathrm{P}<0.05)$, negative emotion has a significant positive correlation to unsafe behavior $(\mathrm{P}<0.01)$, and life satisfaction is significantly negative correlated with unsafe behavior $(\mathrm{P}<0.01)$. Therefore, miners' unsafe behavior is related to subjective well-being in some ways, but it isn't confirmed that if there is a causal relationship between them. Thus, regression analysis is used further to investigate the mechanism of miners' subjective well-being impact on unsafe behavior. 
Table 4. Correlation test of the three dimensions of subjective well-being and unsafe behavior

\begin{tabular}{lccc}
\hline & \multicolumn{3}{c}{ Unsafe behavior } \\
\cline { 2 - 4 } & Pearson correlation & Sig.(2-tailed) & $\mathbf{N}$ \\
\hline Positive emotion & $-.252^{\star}$ & .011 & 184 \\
\hline Negative emotion & $.566^{* *}$ & .000 & 184 \\
\hline Life satisfaction & $-.361^{\star *}$ & .000 & 184 \\
\hline
\end{tabular}

Sig.(2-tailed) represents bilateral approximate $p$ value, at the 0.01 level (two tailed). ${ }^{* \star}$ represents correlation is significant, at the 0.05 level (two tailed). * represents correlation is significant.

Table 5. Multivariate regression analysis results of the three dimensions of subjective well-being and unsafe behavior

\begin{tabular}{lccccc}
\hline & Non-standardized coefficient & Standardized coefficient & t & Sig. & VIF \\
\hline Constant term & 3.508 & & 4.197 & .000 & \\
\hline Positive emotion & -.138 & -.194 & -2.040 & .017 & 1.015 \\
\hline Negative emotion & .452 & .479 & 5.790 & .000 & 1.101 \\
\hline Life satisfaction & -.230 & -.257 & -2.575 & .007 & 1.085 \\
\hline
\end{tabular}

Table 6. Hypotheses testing results

\begin{tabular}{clc}
\hline Hypotheses & Contents & Test results \\
\hline H1 & Miners' subjective well-being is related to their unsafe behavior. & Support \\
\hline H2 & Miners' positive emotion has negative impact on unsafe behavior. & Support \\
\hline H3 & Miners' negative emotion has positive impact on unsafe behavior. & Support \\
\hline H4 & Miners' life satisfaction has negative effect on unsafe behavior. & Support \\
\hline
\end{tabular}

The multivariate regression analysis results of the three dimensions of subjective well-being and unsafe behavior are shown in Table 5 .

It can be seen from Table 5 that there is a strong linear relationship between the three dimensions and unsafe behavior, and the linear relationship model of subjective well-being impact on unsafe behavior is shown in the following formula.

$$
Y=3.508-0.138 X_{1}+0.452 X_{2}-0.23 X_{3}
$$

In the formula, $Y$ represents miners' unsafe behavior, $X_{1}$ represents the positive emotion dimension, $X_{2}$ represents the negative emotion dimension, $X_{3}$ represents life satisfaction dimension. The front coefficients of positive emotion and life satisfaction dimensions are negative, indicating that the higher level of positive emotion and life satisfaction of miners, the fewer unsafe behavior would appear. The front coefficient of negative emotion is positive, indicating that the higher level of miners' negative emotion, the higher probability of unsafe behavior. The results of variance analysis show that the three dimensions have significant impacts on miners' unsafe behavior $(\mathrm{F}=21.525$, Sig. $=0.000<0.01)$.

It is drawn from the coefficients of the linear model that negative emotion has the greatest influence on miners' unsafe behavior, followed by life satisfaction, and positive emotion. Because the investigation object was coal miner, the model is only suitable to the relationship research between miners' subjective well-being and unsafe behavior.

According to all above the analysis results, the hypotheses were verified. They are shown in Table 6.

It can be known form Table 6 that the hypotheses are all supported through the statistical analysis of the questionnaire data.

\section{ADVICES}

According to the results of data inspection and analysis, there are some scientific advices for coal mine managers to reduce miners' unsafe behavior.

First of all, miners' negative emotions should be reduced or eliminated through all methods. Such as encourage miners improve their own mental quality, establish good interpersonal relationships with each other and reduce conflicts between workmates. Coal mine managers could communicate with miners timely in the weekly routine safety inspection meeting, find and overcome the potential negative emotions of miners, remove their psychological pressures, and then, eliminate their possible unsafe behaviors.

Secondly, coal mine managers should pay more attention to miners' positive emotions and life satisfaction. They should strengthen the security management measures and create a safe working atmosphere for their staffs in the daily working life. On the other hand, managers should arrange the work content and rest time reasonably, and then, meet miners' physical and psychological needs timely to improve their positive emotion level and life 
satisfaction. Thus, the employees would have healthy mentality and good living conditions to complete the tough work and reduce the probability of unsafe behavior.

Finally, it is necessary to hire experts to train the miners in safe behavior and give them more systematic studies in safety education, such as emotional control education, security psychology education and safe behavior education.

\section{DISCUSSION}

In contrast to the empirical research made by other scholars (Tay, L., \& Diener, E., 2011), the subjective wellbeing research of this present study was carried out to the coal miners of the specific coal mine industry, which enhanced the practicality of the subjective well-being research. The targeted measures of this research by strengthening the subjective well-being to ensure the behavior safety of employees were important to protect the life and property safety of China's more than 700 million coal miners. These conclusions are consistent with the previous research achievements (Chen, B. W., Van Assche, J., Vansteenkiste, M., Soenens, B., \& Beyers, W., 2015; Ziegler, R., Schlett, C., Casel, K., \& Diehl, M., 2012).

\section{CONCLUSIONS}

1) Miners' subjective well-being can be divided into three dimensions, namely positive emotion, negative emotion and life satisfaction. And the degree of each dimension impact on miners' unsafe behavior is different. It is very important for coal mine managers to develop targeted psychological safety management measures and give more safety education and training according to the different impaction of the three dimensions.

2) As the subjective well-being has a significant impact on miners' unsafe behavior, coal mine managers should make the employees' mental health construction a top priority in the process of safety management, and step into the daily lives of miners to actively understand the life state of each miner. And then, they can ensure miners' safe behavior by satisfying their different subjective well-being.

\section{ACKNOWLEDGEMENTS}

This research is supported by the Excellent Youth Science Foundation of the National Natural Science Foundation of China under Grant No.51422404, Program for the Philosophy and Social Sciences Research of Higher Learning Institutions of Shanxi under Grant No.2015310, and the Graduate Education Reform Research of Shanxi Province in 2015 (No. Jin Study Letter [2015]3). The authors would like to express their great appreciation for the valuable comments and constructive suggestions by the anonymous reviewers and the editor.

\section{REFERENCES}

Chen, B. W., Van Assche, J., Vansteenkiste, M., Soenens, B., \& Beyers, W. (2015). Does psychological need satisfaction matter when environmental or financial safety are at risk? Journal of Happiness Studies, 16(3), 745766. doi:10.1007/s1090

Chen, H., Qi, H., Long, R. Y., \& Zhang, M. L. (2012). Research on 10-year tendency of China coal mine accidents and the characteristics of human factors. Safety Science, 50(4), 745-750. doi:10.1016/j.ssci.2011.08.040

Chu, K. H. L., Murrmann, S. K. (2006). Development and validation of the hospitality emotional labor scale. Tourism Management, 27(6), 1181-1191. doi:10.1016/j.tourman.2005.12.011

Kushlev, K., Heintzelman, S. J., Lutes, L. D., Wirtz, D., Oishi, S., \& Diener, E. (2017). ENHANCE: Design and rationale of a randomized controlled trial for promoting enduring happiness \& well-being. Contemporary Clinical Trials, 52(1), 62-74. doi:10.1016/j.cct.2016.11.003

Li, F., Jiang, L., Yao, X., \& Li, Y. J. (2013). Job demands, job resources and safety outcomes: The roles of emotional exhaustion and safety compliance. Accident Analysis $\mathcal{E}$ Prevention, 51(3), 243-251. doi:10.1016/j.aap.2012.11.029.

Li, J. Z., Zhang, Y. P., Liu, X. G., Liu, Y. L., \& Wang, T. R. (2017). Impact of conflict management strategies on the generation mechanism of miners' unsafe behavior tendency. EURASIA Journal of Mathematics, Science $\mathcal{E}$ Technology Education, 13(6), 2721-2732. doi:https:// doi.org/10.12973/eurasia.2017.01249a

Li, N. W., \& Ji, D. J. (2011). Application study on behavior-based safety in coal mine behavior management. China Safety Science Journal, 21(12), 115-121. doi:10.16265/j.cnki.issn10 03-3033.2011.12.019

Liu, G. Y., \& Luo, C. L. (2012). Analysis of the safety psychological factors in the coal mine safety management. Procedia Engineering, 45(8), 253-258. doi:10.1016/j.proeng.2012.08.153 
Tay, L., \& Diener, E. (2011). Needs and subjective well-being around the world. Journal of Personality and Social Psychology, 101(2), 354-365. doi:10.1037/a0023779

Zhang, Y. T., Wei, X. X., \& Li, J. Z. (2015). Study on trait anxiety status and unsafe mentality of miners. Safety in Coal Mines, 46(7), 245-248. doi:10.13347/j.cnki.mkaq.2015. 07.069

Ziegler, R., Schlett, C., Casel, K., \& Diehl, M. (2012). The role of job satisfaction, job ambivalence, and emotions at work in predicting organizational citizenship behavior. Journal of Personnel Psychology, 11, 176-190. doi:10.1027/1866-5888/a000071

\section{http://www.ejmste.com}

